\title{
Detection of Drug Resistant Mycobacterium tuberculosis among Patients with and without HIV Infection in a Rural Setting
}

\author{
R Kurup, C George
}

\begin{abstract}
Objective: To analyse the sensitivity of Mycobacterium tuberculosis by nitrate reductase assay (NRA) and the Hain molecular line probe assay (LPA) in sputa of tuberculosis (TB)/HIV co-infected patients in Guyana.

Design: Sputum samples were collected from known TB patients at Georgetown Chest Clinic and were analysed at the Reference Laboratory, Guyana, over the period April 2010 to April 2011.

Results: Both methods recorded greater sensitivity for rifampin (RIF) than of isoniazid (INH). Both methods detected four RIF resistant, two INH resistant and two multi-drug resistant (MDR) strains and they had greater negative agreement indices than positive agreement indices.

Conclusion: It was established that the sensitivity of Mycobacterium tuberculosis by the NRA and Hain LPA in TB/HIV co-infected patients has acceptable correlation and that HIV infection does not affect drug susceptibility testing.
\end{abstract}

Keywords: Diagnostics, line probe assay, nitrate reductase assay, rural settings, tuberculosis

\section{Detección de Mycobacterium tubersulosis Resistente a los Antibióticos entre Pacientes con y sin Infección por VIH en un Área Rural \\ R Kurup, C George}

\begin{abstract}
RESUMEN
Objetivo: Analizar la sensibilidad de Mycobacterium tuberculosis por medio del ensayo de nitrato reductasa (NRA) y el ensayo de sonda lineal (LPA) molecular de Hain en esputos de pacientes coinfectados TB/VIH en Guyana.

Diseño: Muestras de esputo de pacientes de la Clínica del Tórax en Georgetown diagnosticados con tuberculosis, fueron analizadas en el Laboratorio de Referencias, en Guyana, en el periodo de abril de 2010 a abril de 2011.

Resultados: Ambos métodos registraron una mayor sensibilidad a la rifampicina (RIF) que a la isoniacida (INH). Ambos métodos detectaron cuatro cepas resistentes a RIF, dos resistentes a INH, y dos resistentes a mútiples medicamentos (RMM). Asimismo, presentaban mayores índices de concordancia negativa que de concordancia positiva.

Conclusión: Se estableció que la sensibilidad de Mycobacterium tuberculosis por medio del ensayo de NRA y el LPA de Hain en pacientes co-infectados TB/VIH, guarda una correlación aceptable, y que la infección por VIH no afecta la prueba de susceptibilidad a los medicamentos.
\end{abstract}

Palabras claves: Diagnóstico, ensayo de sonda lineal, ensayo de nitrato reductasa, áreas rurales, tuberculosis

West Indian Med J 2013; 62 (2): 122

From: Faculty of Health Sciences, University of Guyana, Guyana, South America.

Correspondence: Dr R Kurup, Faculty of Health Sciences, University of Guyana, Georgetown, Guyana, South America. E-mail: kuruprajini@ yahoo.com

\section{INTRODUCTION}

Tuberculosis (TB) continues to be a major public health problem, particularly in developing countries. In 2009, the World Health Organization (WHO) estimated 9.4 million new cases globally with most of the burden in developing countries which had $95 \%$ of the cases (1). The impact of 
$\mathrm{TB} / \mathrm{HIV}$ co-infection is worrisome. HIV is the strongest risk factor for developing active TB among those with latent TB infection [LTBI] (2). On the other hand, TB is one of the main causes of mortality in people living with HIV. In 2009, TB mortality among HIV-positive and HIV-negative persons was estimated in 0.38 million and 1.3 million people, respectively (3). By March 2010, 58 countries have reported at least one extensively drug-resistant (XDR)-TB case (1).

In Guyana, the tuberculosis situation has changed significantly over the last 15 years. A steady increase in the number of TB cases was noted since the early 1990s after a substantial decrease during the 1970s and 1980s (4). The case notification rate increased from 21 per 100000 in 1992 to 83 per 100000 in 2009 . The mortality rate is gradually declining: from 16 deaths per 100000 population in 2004 to 11 deaths per 100000 population in 2008 (4). During the last few years, several diagnostic methods have been developed for the rapid detection of drug resistance and for drug susceptibility testing (DST) of Mycobacterium tuberculosis (5-8). Most important among them were line probe assay (LPA) - an expensive, molecular tool, and nitrate reductase assay (NRA) - a rapid, inexpensive method (9). In 2011, WHO reported multi-drug resistant (MDR)-TB diagnostic tools on the sensitivity of rapid cultures compared to molecular assay [Table 1] (10).
For the LPA, DNA strip assays targeting rpoB, katG and inhA (GenoType MTBDRplus; Hain Lifescience GmbH, Nehren, Germany) genes were used for $M$ tuberculosis identification and detection of resistance to rifampin (RIF) and isoniazid (INH). The DNA strip assays are based on a multiplex polymerase chain reaction (PCR) in combination with reverse hybridization. Either the omission of a wild-type band or the appearance of bands of DNA signals representing specific mutations indicates the existence of a resistant strain. The entire procedure is divided into four steps:

- DNA extraction from cultured material (plates/ liquid medium) and clinical specimens (sputum).

- A multiplex PCR amplification with biotinylated primers.

- Hybridization - reverse process which involves chemical denaturation of the amplification products, hybridization of the single stranded, biotin labelled amplicons to membrane bound probes, stringent washing, addition of a streptavidin/ alkaline phosphatase conjugate, and an AP mediated staining reaction.

- Evaluation - pasting of strips on template worksheets, interpretation of results using MTBDR plus chart.

Table 1: World Health Organization-endorsed multi-drug resistant (MDR) diagnostic tools (WHO 2011)

\begin{tabular}{|c|c|c|c|c|c|}
\hline Test family & Tests within test family & Sens for $\mathrm{H}$ & Spec for $H$ & Sens for $R$ & Spec for $R$ \\
\hline \multirow{4}{*}{ Rapid cultures } & Liquid culture and DST & $\begin{array}{l}100 \text { (if done } \\
\text { on smear }+ \text { ) }\end{array}$ & $\begin{array}{l}100 \text { (if done } \\
\text { on smear }+ \text { ) }\end{array}$ & $\begin{array}{l}100 \text { (if done } \\
\text { on smear }+ \text { ) }\end{array}$ & $\begin{array}{l}100 \text { (if done } \\
\text { on smear }+ \text { ) }\end{array}$ \\
\hline & Non-commercial rapid cultures & & & & \\
\hline & MODS & $94-99$ & $88-99$ & $94-99$ & $95-100$ \\
\hline & NRA & $95-98$ & $99-100$ & $95-98$ & $99-100$ \\
\hline \multirow{3}{*}{ Molecular assay } & Line probe assays (Hain & & & & \\
\hline & GenoType MTBDRplus) & $76-90$ & $97-100$ & $95-99$ & $97-99$ \\
\hline & Automated NAAT (Xpert) & NA & NA & $94-99$ & $96-99$ \\
\hline
\end{tabular}

Sens: sensitivity, Spec: specificity, H: isoniazid, R: rifampin, MODS: microscopic observation drug susceptibility, NRA: nitrate reductase assay

This research therefore is a first attempt to compare the sensitivity of the Griess NRA and the Hain LPA among TB/HIV co-infected patients and TB positive HIV negative patients for DST of 50 clinical isolates of $M$ tuberculosis to first-line drugs.

\section{MATERIALS AND METHODS}

Sputum samples were collected from the Georgetown Hospitals Chest Clinic and the test done at Reference Laboratory from April 2010 to April 2011 using a stratified random sample. The sputum samples of twenty-five TB/HIV co-infected patients and twenty-five TB positive HIV negative patients for the specified period were extracted. The data were examined based on treatment history and results of HIV test (serologic) at the time of TB diagnosis.
Nitrate reduction assay is based on the ability of $M$ tuberculosis to reduce nitrate to nitrite. This is routinely used for biochemical identification of mycobacterial species. The presence of nitrite can easily be detected with specific reagents, which produce a colour change. Nitrate reduction assay uses the detection of nitrite as an indication of growth when it is used as a drug susceptibility test.

Four LJ tubes per specimen (two controls, one containing INH and one containing RIF) were labelled. In a biological safety cabinet (BSC), $0.2 \mathrm{ml}$ (four drops) of processed specimen was inoculated to each of the four tubes. The caps of the tubes were left slightly open and incubation was in a slanted position for three days to allow excess moisture to evaporate. After three days, the caps were tightly closed and incubated in an upright position at $37^{\circ} \mathrm{C}$ for 28 
days. Cultures were tested weekly for presence of growth. The LJs showing evidence of growth on the control tube were tested with Griess before 28 days. After 28 days incubation or if growth is seen in the control tubes, the tubes were removed from the incubator and placed in BSC. Using all safety precautions and wearing personal protective equipment (N95 masks, gown and gloves), one control tube was opened slowly and $0.5 \mathrm{ml}$ Griess reagent was added to the tube with a sterile plastic pipette. Development of a red colour indicated that there was growth on the slant and that the nitrate in the LJ media was converted to nitrite. If a red colour was observed in the control, then an equal amount of Griess reagent was added to the slant containing INH and RIF. Observation of red colour in the control and drug tubes indicated that there was growth in the drug tubes despite the presence of drugs. This indicated that the isolate was resistant to the drugs. Red colour observed in the control tube and no colour in the drug tubes indicated that growth of mycobacteria was inhibited by the presence of the drugs and in this case the isolate was sensitive to the drugs.

\section{Statistical analysis}

As the diagnostic methods tested in this study do not have a gold standard, a Bayesian approach was used. The agreement between the two tests was evaluated by calculating positive and negative agreement indices according to the theory proposed by Graham and Bull (11). Considering the readings of the two tests reported as either positive or negative, the values $\mathrm{a}, \mathrm{b}, \mathrm{c}$ and $\mathrm{d}$ denote the observed frequencies for each possible combination of ratings by tests 1 and 2.

$\mathrm{a}=$ the number of samples positive with both tests

$\mathrm{b}=$ the number of samples negative with test 1 and positive with test 2

$\mathrm{c}=$ the number of samples positive with test 1 and negative with test 2

$\mathrm{d}=$ the number of samples negative with both tests.

The proportion of specific agreement for the overall agreement $\left(\mathrm{P}_{0}\right)$, the positive ratings $\left(\mathrm{P}_{\text {pos }}\right)$ [the positive agreement index] and for the negative ratings $\left(\mathrm{P}_{\text {neg }}\right)$ [the negative agreement index] were calculated as follows:

$\mathrm{P}_{\mathrm{o}}=(\mathrm{a}+\mathrm{d}) /$ total

$\mathrm{P}_{\text {pos }}=2 \mathrm{a} / 2 \mathrm{a}+\mathrm{b}+\mathrm{c}$

$P_{\text {neg }}=2 d / 2 d+b+c$

This method excluded the limitation of the kappa statistics. Data were entered in Microsoft Excel and later transferred to SPSS 13.0 for analysis. A $p$-value less than 0.05 was considered significant.

\section{Ethical Consideration}

Ethics approval for the conduct of this study was obtained from the Institutional Review Board (IRB) of the Ministry of Health of Guyana.

\section{RESULTS}

Fifty clinical isolates of $M$ tuberculosis were analysed using the NRA and LPA methods. Twenty-five clinical isolates were from known HIV positive tuberculosis patients and twenty-five HIV negative tuberculosis patients. The Figure shows the algorithm of selection of clinical isolates at the

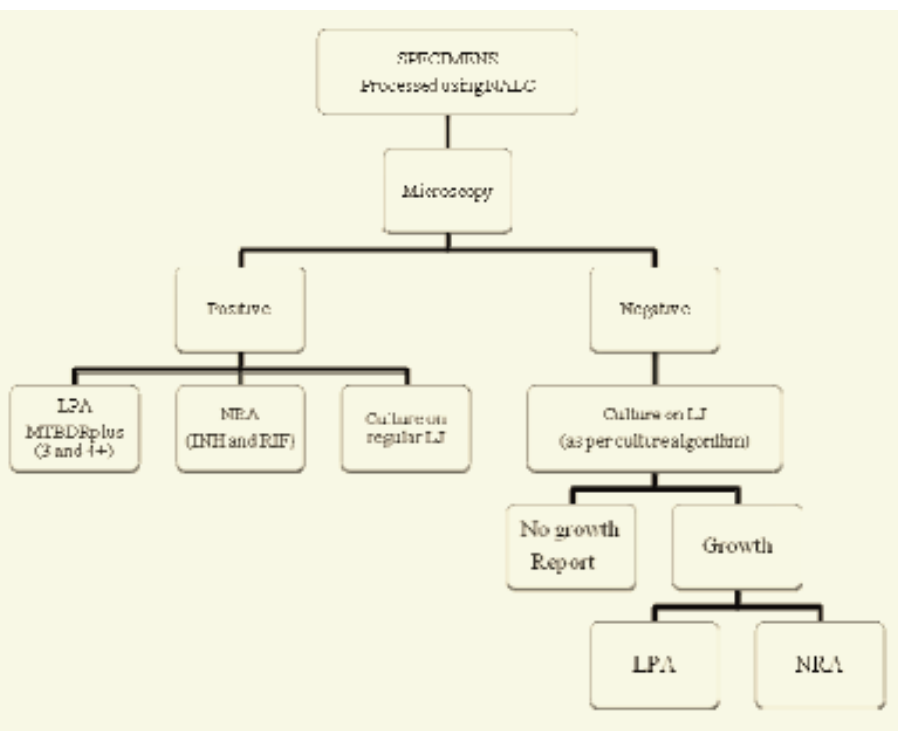

Figure: Testing algorithm for tuberculosis in Reference Laboratory, Guyana

laboratory in Guyana. The results obtained with NRA compared to the LPA method is shown in Table 2. For isoniazid, two isolates were found resistant and 30 susceptible by both methods. Eighteen isolates gave discordant results since they were resistant by NRA but susceptible by LPA.

For rifampicin, eight isolates were resistant and 34 susceptible by both methods; four strains gave a discordant result, being susceptible by LPA but resistant by NRA, and four susceptible by NRA and resistant by LPA. For MDR strains (RIF + INH), two isolates were resistant and 43 susceptible by both methods. Five isolates were susceptible by LPA but resistant by NRA.

The agreement between the results obtained by NRA and LPA was estimated by calculating positive and negative agreement indices. The indices in Table 2 show that among RIF, INH and MDR, the agreement was better in negative rather than in the positive direction.

A summary of LPA results and NRA results with monoresistance and multi-resistance is shown in Table 3. A total of 24 isolates were sensitive by both methods. Table 4 shows the results obtained with NRA compared to LPA among HIV positive and HIV negative clinical isolates of M tuberculosis. Within the HIV positive cases, LPA showed one was INH resistant and four were RIF resistant; NRA method showed nine INH resistant and four RIF resistant. Within the HIV negative cases, LPA had one INH resistant and eight RIF 
Table 2: Comparison of results of drug-susceptibility testing of 50 strains of Mycobacterium tuberculosis by line probe assay (LPA) and nitrate reductase assay (NRA)

\begin{tabular}{|c|c|c|c|c|c|c|}
\hline & \multirow[t]{2}{*}{ NRA } & \multicolumn{2}{|c|}{ LPA } & \multirow[b]{2}{*}{ Positive AI (\%) (CI) } & \multirow[b]{2}{*}{ Negative AI (\%) (CI) } & \multirow[b]{2}{*}{ Overall agreement $\left(\mathrm{P}_{\mathrm{o}}\right)$} \\
\hline & & Resistant & Susceptible & & & \\
\hline \multirow[t]{3}{*}{ Rifampicin (RIF) } & Resistant & 8 & 4 & & & \\
\hline & Susceptible & 4 & 34 & $66.6(44.8-88.4)$ & $89.5(82.2-96.7)$ & 84.0 \\
\hline & Resistant & 2 & 18 & & & \\
\hline Isoniazid (INH) & Susceptible & 0 & 30 & $18.2(0.4-39.2)$ & $76.9(66.6-87.3)$ & 64.0 \\
\hline Multi-drug & Resistant & 2 & 5 & & & \\
\hline $\begin{array}{l}\text { resistant } \\
(\text { RIF + INH) }\end{array}$ & Susceptible & 0 & 43 & $44.4(39.5-84.9)$ & $94.5(89.7-99.3)$ & 90.0 \\
\hline
\end{tabular}

Table 3: Performance of line probe assay (LPA) compared with nitrate reductase assay (NRA) among 50 strains of Mycobacterium tuberculosis

\begin{tabular}{lccccc}
\hline & \multicolumn{5}{c}{ LPA } \\
\cline { 2 - 6 } NRA & MDR & $\mathrm{INH}^{\mathrm{R}}$ & $\mathrm{RIF}^{\mathrm{R}}$ & $\mathrm{INH}^{\mathrm{S}} \mathrm{RIF}^{\mathrm{S}}$ & Total \\
& & & & & \\
MDR & 2 & 0 & 3 & 2 & 7 \\
$\mathrm{INH}^{\mathrm{R}}$ & 0 & 0 & 3 & 10 & 13 \\
$\mathrm{RIF}^{\mathrm{R}}$ & 0 & 0 & 3 & 2 & 5 \\
$\mathrm{INH}^{\mathrm{S}} \mathrm{RIF}^{\mathrm{S}}$ & 0 & 0 & 1 & 24 & 25 \\
Total & 2 & 0 & 10 & 38 & 50 \\
\hline
\end{tabular}

MDR: multi-drug resistant, INH: isoniazid, RIF: rifampin

Table 4: Performance of line probe assay (LPA) compared with nitrate reductase assay (NRA) among HIV positive and HIV negative cases of Mycobacterium tuberculosis

\begin{tabular}{cccc}
\hline & & \multicolumn{2}{c}{ HIV } \\
\cline { 3 - 4 } & & Positive & Negative \\
\hline \multirow{6}{*}{ LPA } & $\mathrm{INH}^{\mathrm{R}}$ & 1 & 1 \\
& $\mathrm{INH}^{\mathrm{S}}$ & 24 & 24 \\
& & & 8 \\
& $\mathrm{RIF}^{\mathrm{R}}$ & 4 & 17 \\
& $\mathrm{RIF}^{\mathrm{S}}$ & 21 & 11 \\
& $\mathrm{INH}^{\mathrm{R}}$ & 9 & 14 \\
& $\mathrm{INH}^{\mathrm{S}}$ & 16 & 8 \\
& & & 17 \\
& $\mathrm{RIF}^{\mathrm{R}}$ & 4 & \\
& $\mathrm{RIF}^{\mathrm{S}}$ & 21 & \\
\hline
\end{tabular}

INH: isoniazid, RIF: rifampin

resistant whereas NRA had 11 INH resistant and eight RIF resistant.

\section{DISCUSSION}

Tuberculosis remains a major health problem in the world. The epidemic caused by HIV has increased the burden of TB, especially in populations where the prevalence of HIV infec- tion is high. Additionally, the incidence of drug-resistant TB has presented new threats to the existing public health problem of TB/HIV co-infection.

In this study, the Griess NRA was compared to the Hain LPA using samples collected from TB/HIV co-infected patients.

Other studies showed LPA had high specificity for detection of RIF and INH, high sensitivity for detection of RIF resistance and somewhat lower sensitivity for INH (12, 13). There are some issues which are important while performing LPA in high TB burden countries such as room facility to minimize the risk of contamination. Restricted access to the molecular laboratories and strict adherence to standard operating procedures are necessary to reduce the risk of amplicon contamination. Thus, LPA is expensive compared to NRA in rural settings.

Nitrate reductase assay, as observed in the present study, was found to be rapid, inexpensive and easy to perform. As it does not require much instrumentation, it could be used routinely in laboratories in developing countries for drug susceptibility testing of $M$ tuberculosis. It might be possible to apply the nitrate reductase test directly to microscopy positive sputa, thus drastically reducing the time needed for detection of drug resistant $M$ tuberculosis.

Other studies have shown excellent results with sensitivity, specificity and kappa agreement for detection of resistance to RIF, INH and MDR-TB (14-16). Therefore, according to the WHO, validated methods that detect resistance within 2-3 weeks can be recommended for rapid testing in places where molecular methods are not available (17). In the United States of America, HIV-positive MDRTB cases initially had $100 \%$ mortality (18), but with greater awareness and earlier diagnosis, an improvement in initial survival rates of up to $50 \%$ has been reported (19). In most patients, MDR-TB remains infectious throughout suboptimal therapy designed for drug-susceptible tuberculosis. Greater use of drug susceptibility testing would allow appropriate therapy and improve prognosis and potentially reduce MDRTB transmission (20-22). Early diagnosis of MDR-TB is very important to prevent therapy with inappropriate regimes 
from causing MDR-TB strains to develop additional resistance (23). In this study, NRA detected 20 INH resistant strains whereas LPA detected only two strains of INH resistant. There was not much significant difference between HIV positive and HIV negative sample testing.

Overall, the performances of LPA and NRA were excellent in detecting RIF-resistant strains rather than INH. The study concludes that LPA is an appropriate tool for rapid screening for MDR-TB in a reference laboratory setting and takes less time. But the infrastructure, training, quality assurance and other requirements should be followed to ensure high quality results. In Guyana, the NRA method could do a better job within the limited infrastructure for MDR-TB management.

\section{REFERENCES}

1. World Health Organization. Global tuberculosis control. WHO/HTM/ TB/2010.7. Geneva, Switzerland: WHO; 2010.

2. Rieder HL. Epidemiologic basis of tuberculosis control. Paris: International Union Against Tuberculosis and Lung Disease; 2003.

3. World Health Organization. Global tubercolosis control. Geneva: WHO; 2010.

4. National Tuberculosis Control Program Annual Report 2010 Georgetown: Ministry of Health; 2010.

5. McNerney R, Kiepiela P, Bishop KS, Nye PM, Stoker NG. Rapid screening of Mycobacterium tuberculosis for susceptibility to rifampicin and streptomycin. Int J Tuberc Lung Dis 2000; 4: 69-75.

6. Rossau R, Traore H, De Beenhouwer H, Mijs W, Jannes G, Rijk P et al. Evaluation of the INNO-LiPA Rif. TB assay, a reverse hybridization assay for the simultaneous detection of Mycobacterium tuberculosis complex and its resistance to rifampin. Antimicrob Agents Chemother 1997; 41: 2093-8.

7. Palomino JC, Traore H, Fissette K, Portaels F. Evaluation of mycobacteria growth indicator tube (MGIT) for drug susceptibility testing of Mycobacterium tuberculosis. Int J Tuberc Lung Dis 1999; 3: 344-8.

8. Foongladda S, Roengsanthia D, Arjrattanakool W, Chuchottaworn C, Chaiprasert A, Franzblau SG. Rapid and simple MTT method for rifampicin and isoniazid susceptibility testing of Mycobacterium tuberculosis. Int J Tuberc Lung Dis 2002; 6: 1118-22.

9. Angeby KA, Klintz L, Hoffner SE. Rapid and inexpensive drug susceptibility testing of Mycobacterium tuberculosis with a nitrate reductase assay. J Clin Microbiol 2002; 40: 553-5.
10. World Health Organization. Annex 1. Methods for evidence reviews and modeling. WHO/HTM/TB/2011.6a; Geneva: World Health Organization; 2011. Available from: http://whqlibdoc.who.int/hq/2011/ WHO_HTM_TB_2011.6a_eng.pdf

11. Graham P, Bull B. Approximate standard errors and confidence intervals for the indices of positive and negative agreement. J Clinical Epid 1998; 51: 763-71.

12. Ling D, Zwerling A, Pai M. GenoType MTBDR assays for the diagnosis of multidrug-resistant tuberculosis: a meta-analysis. Eur Respir J 2008; 32: 1165-74.

13. Albert H, Bwanga F, Mukkada S, Nyesiga B, Ademun JP, Lukyamuzi G et al. Rapid screening of MDR-TB using molecular line probe assay is feasible in Uganda. BMC Infect Dis 2010; 10: 41.

14. Bwanga F, Hoffner S, Haile M, Joloba ML. Direct susceptibility testing for multi drug resistant tuberculosis: A meta-analysis. BMC Infect Dis 2009; 9: 67.

15. Visalakshi P, Meharwal SK, Myneedu VP, Behera D. Evaluation of direct method of drug susceptibility testing of Mycobacterium tuberculosis to rifampicin and isoniazid by nitrate reductase assay in a national reference laboratory. Diagn Microbiol Infect Dis 2010; 66: $148-52$.

16. Bwanga F, Haile M, Joloba ML, Ochom E, Hoffner S. Direct nitrate reductase assay versus microscopic observation drug susceptibility test for rapid detection of MDR-TB in Uganda. PLoS One 2011; 6: e19565.

17. World Health Organization. Guidelines for the programmatic management of drug-resistant tuberculosis. Emergency update 2008. WHO/HTM/TB/2008.402. Geneva: WHO; 2008.

18. Small PM, Shafer RW, Hopewell PC, Singh SP, Murphy MJ, Desmond E et al. Exogenous re-infection with multidrug resistant Mycobacterium tuberculosis in patients with advanced HIV disease. N Engl J Med 1993; 328: 1137-44.

19. Salomon N, Perlman DC, Friedman P, Buchstein S, Krelwirth BN, Mildvan D. Predictors and outcome of multidrug-resistant tuberculosis. Clin Infect Dis 1995; 21: 1245-52.

20. Mitnick C, Bayona J, Palacios E, Shin S, Furin J, Alcantara F et al. Community-based therapy for multidrug-resistant tuberculosis in Lima, Peru. N Engl J Med 2003; 348: 119-28.

21. Farmer P, Kim JY. Community-based approaches to the control of multidrug resistant tuberculosis: introducing DOTS-plus. BMJ 1998; 317: $671-4$.

22. Kawai V, Soto G, Gilman RH, Bautista CT, Caviedes L, Huaroto L et al. Tuberculosis mortality, drug resistance, and infectiousness in patients with and without HIV infection in Peru. Am J Trop Med Hyg 2006; 75: 1027-33.

23. Furin JJ, Becerra MC, Shin SS, Kim JY, Bayona J, Farmer PE. Effect of administering short-course, standardized regimens in individuals infected with drug-resistant Mycobacterium tuberculosis strains. Eur J Clin Microbiol Infect Dis 2000; 19: 132-6. 